Research article

Open Access

\title{
Isolation, Identific ation, and \\ Characterization of One \\ Degradation Product in Ambroxol by HPLC-Hyphenated Techniques
}

\author{
Veera Raghava Raju Thummala * 1 , \\ Mrutyunjaya Rao IVATURI ${ }^{2}$, Someswara Rao NITTALA ${ }^{2}$
}

\footnotetext{
${ }^{1}$ Analytical Research and Development, Integrated Product Development, Dr. Reddy's Laboratories Ltd., Bachupally, Hyderabad-500 072, India.

${ }^{2}$ School of Chemistry, Andhra University, Visakhapatnam-530003, A.P., India.

* Corresponding author. E-mail: tvr_raju@rediffmail.com (V. R. R. Thummala)

Sci Pharm. 2014; 82: 247-263

doi:10.3797/scipharm.1310-21

Published: January $12^{\text {th }} 2014$

Accepted: January $12^{\text {th }} 2014$

Received: $\quad$ October $24^{\text {th }} 2013$

This article is available from: http://dx.doi.org/10.3797/scipharm.1310-21

(c) Thummala et al.; licensee Österreichische Apotheker-Verlagsgesellschaft m. b. H., Vienna, Austria.

This is an Open Access article distributed under the terms of the Creative Commons Attribution License (http://creativecommons.org/licenses/by/3.0/), which permits unrestricted use, distribution, and reproduction in any medium, provided the original work is properly cited.
}

\begin{abstract}
This study details the isolation, identification, and characterization of ambroxol's unknown impurity. One unknown impurity of ambroxol was formed in the formulated drug under stress conditions $\left[40^{\circ} \mathrm{C} / 75 \%\right.$ relative humidity $(\mathrm{RH})$ for 6 months] with the relative retention time (RRT) 0.68 in RP-HPLC. The impurity was enriched by exposing it to heat and it was isolated by using preparative HPLC. The enriched impurity was purified and characterized using the following sophisticated techniques: 2D NMR (gDQ-COSY, gHSQC, and gHMBC), FTIR, and LC-MS/MS. On the basis of the spectral data, the impurity was characterized as trans-4-(6,8-dibromoquinazolin-3(4H)-yl)cyclohexanol.
\end{abstract}

\section{Keywords}

Ambroxol • RP-HPLC • Unknown impurity • NMR • LC-MS/MS

\section{Introduction}

Ambroxol hydrochloride, chemically trans-4-[(2-amino-3,5-dibromobenzyl)amino]cyclohexanol hydrochloride [1], is a semi-synthetic derivative of vasicine from the Indian shrub "Adhatoda vasica". It is an expectoration improver and a mucolytic agent used in the treatment of bronchial asthma and chronic bronchitis. Ambroxol hydrochloride has also 
been reported to have cough-suppressing effects and anti-inflammatory action. Recently, the inhibition of nitric oxide-dependent activation of soluble guanylate cyclase was suggested to be one of the molecular mechanisms of therapeutic action of ambroxol hydrochloride, also used in pulmonary alveolar proteinosis in pulmonary distress and infant respiratory distress syndrome. The molecular structure is shown in Fig. 1.

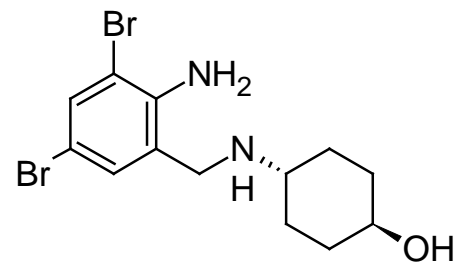

Ambroxol

Fig. 1. Structure of Ambroxol

In general, solid active pharmaceutical ingredients (APIs) are formulated with excipients as tablets, syrup and/or capsules. Since the active ingredient interacts with the excipients and the formulated product is stored at different conditions, the study of API stability is critical in the drug development process. Many factors can affect the stability of a pharmaceutical product, some of them include the stability of the active ingredient, the manufacturing process, the environmental conditions (such as heat, light, and moisture during storage), as well as some chemical reactions such as oxidation, reduction, hydrolysis, and racemization that might occur $[2,3]$. The study of stability under stressed conditions is important since it can cause many degradation reactions.

Several spectrophotometric methods have been reported for the qualitative and quantitative determination of AMB from pharmaceutical formulations [6-9]. Various other methods such as HPLC [10-13], GLC [14, 15], the sequential injection technique coupled with a monolithic column [16], LC-MS [17], capillary electrophoretic [18] and fluorescence detection [19] are also reported for its determination from biological fluids. A few of the degradants and other impurities of ambroxol reported in the British Pharmacopiea [5] are shown in Fig. 2. One unknown impurity was observed during the stability study of ambroxol syrup. This impurity was observed to be at more than the identification threshold as per ICH guidelines [4]. None of the literature methods discussed the identification of unknown impurities during stability studies of ambroxol.

The present article deals with the identification and characterization of one unknown degradant impurity formed during the storage of the drug product at stressed conditions $\left[40^{\circ} \mathrm{C} / 75 \%\right.$ relative humidity $\left.\mathrm{RH}\right]$ for 6 months. This impurity was isolated by preparative HPLC and the structure was confirmed using FTIR, LC-MS/MS, and NMR spectroscopy.

HPLC-hyphenated techniques are now widely used for the structure elucidation of trace amounts of the degradation products without a complicated isolation process. LC-MS/MS has been one of the powerful techniques for the identification of small quantities of drug degradation products [20]. In the present study, the impurity was isolated by preparative HPLC and characterized by FTIR, NMR, and LC-MS/MS. 


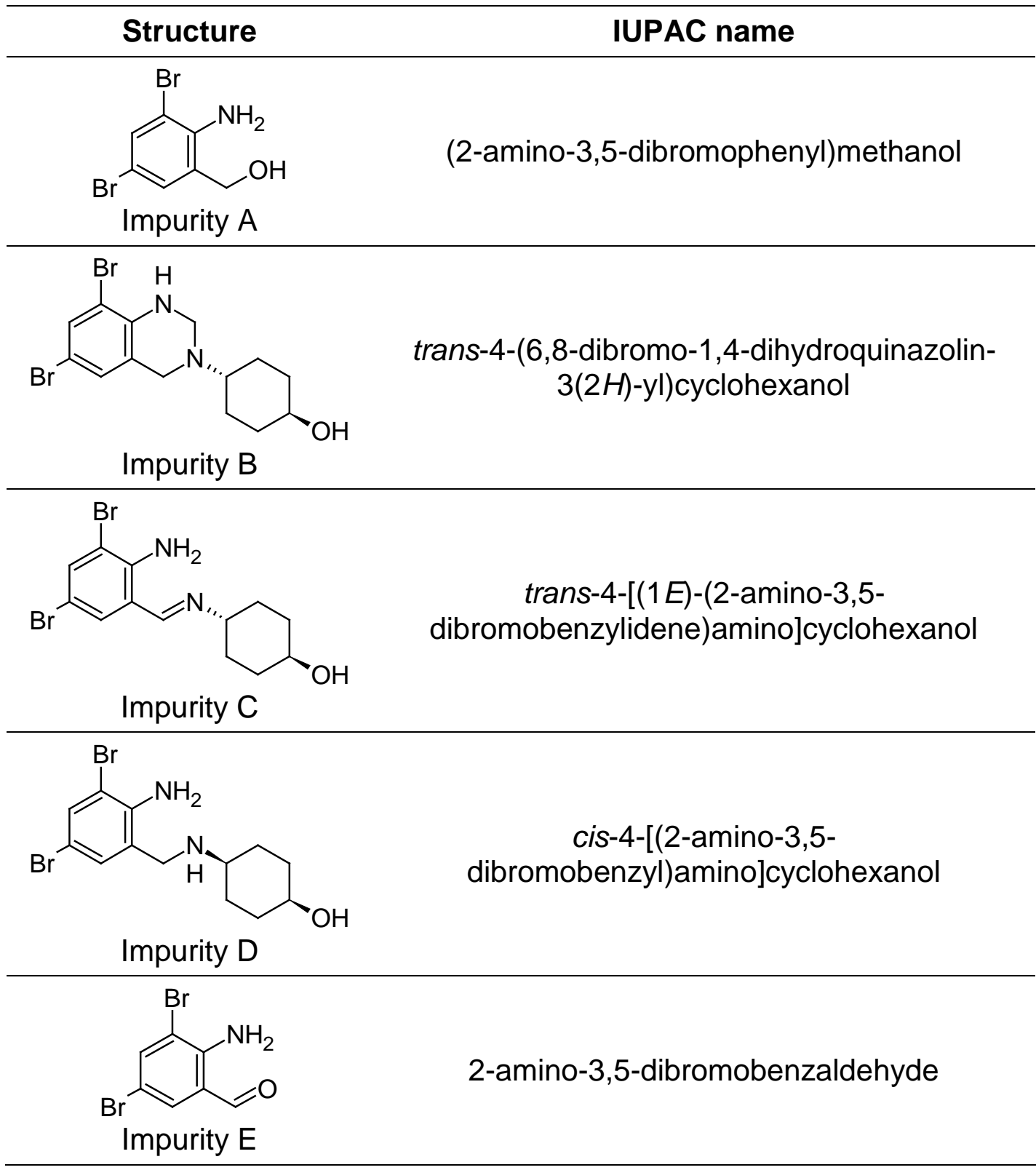

Fig. 2. Structures of ambroxol's known impurities

\section{Experimental}

\section{Chemicals, Reagents, and Samples}

Ambroxol syrup was received from the formulation research and development laboratory of Dr. Reddy's Laboratories Ltd., IPDO, Hyderabad, India. Diammonium hydrogen phosphate was procured from Merck, Germany. HPLC grade acetonitrile, methanol, and orthophosphoric acid were purchased from Merck, Germany. High purity water was prepared by using the Millipore Milli-Q plus purification system. 


\section{Chromatographic Conditions for HPLC}

HPLC measurements were carried out using a reversed-phase Waters Symmetry C18, $250 \times 4.6 \mathrm{~mm}, 5 \mu$ particle size column operated at $25^{\circ} \mathrm{C}$ with gradient elution at $0.8 \mathrm{~mL}$ $\min ^{-1}$ using the mobile phase buffer $0.01 \mathrm{M}$ diammonium hydrogen phosphate of $\mathrm{pH} 7.0$ ( $\mathrm{pH}$-adjusted with dilute orthophosphoric acid solution); UV absorbance at $248 \mathrm{~nm}$; injection volume $10 \mu \mathrm{L}$. Mobile phase A consisted of a pH 7.0 phosphate buffer and acetonitrile $(80: 20 \mathrm{v} / \mathrm{v})$; mobile phase $\mathrm{B}$ consisted of a pH 7.0 phosphate buffer, acetonitrile, and methanol $(20: 75: 5 \mathrm{v} / \mathrm{v} / \mathrm{v})$. The LC gradient program was set as: time (min)/\% mobile phase B: $0.01 / 25,45 / 60,50 / 75,55 / 75,60 / 25$, and 65/25. A mixture of water and acetonitrile (50:50 v/v) was used as diluent for the sample preparation.

\section{Isolation of the Unknown Impurity by Preparative HPLC}

\section{Enriching the Unknown Impurity}

Ambroxol syrup was exposed to heat at $105^{\circ} \mathrm{C}$ for 5 days. The stressed syrup equivalent to $1000 \mathrm{mg}$ of ambroxol was transferred into a 50-ml volumetric flask. $30 \mathrm{ml}$ of diluent was added and the sample was sonicated for 30 minutes with intermediate shaking. It was then made up to volume with diluent $(20 \mathrm{mg} / \mathrm{ml})$. This solution was injected into the liquid chromatography. The observed degradation was $10.35 \%$.

\section{Chromatographic Conditions for Preparative HPLC and Preparative Isolation}

Preparative HPLC was performed using a reversed-phase Inertsil C18 column (250_20mm i.d., $5 \mathrm{~mm}$, Zodiac Silica Company) on the Agilent Preparative HPLC system. Mobile phase A consisted of water and acetonitrile in the ratio of 80:20 (v/v), respectively. Mobile phase B consisted of acetonitrile and water in the ratio of 80:20 (v/v), respectively. Preparative HPLC was carried out at a flow rate of $15 \mathrm{~mL} / \mathrm{min}$, the column oven temperature was maintained at ambient conditions, and the Rheodyne injector was used for injecting the samples into the chromatographic system. The gradient program for Impurity I followed was time ( $\min ) / \%$ mobile phase $\mathrm{B}: 0 / 5,12 / 5,16 / 85,32 / 85,36 / 5$, and 40/5). Peak cut criteria for the isolated impurity was set based on the peak retention time. Fractions $>95 \%$ purity were pooled together and concentrated by the Rotavapor to remove solvents, then lyophilized using freeze drying to obtain a pure compound with greater than $98 \%$ purity.

\section{NMR}

The ${ }^{1} \mathrm{H}$ and ${ }^{13} \mathrm{C}$ NMR data for ambroxol's unknown impurity was recorded in $\mathrm{CDCl}_{3}$ at 500 $\mathrm{MHz}$ and $125 \mathrm{MHz}$, respectively, on the Varian Unity Innova $500 \mathrm{MHz}$ spectrometer. The chemical shift values were reported on the $\delta$ scale in ppm with respect to TMS $(\delta=0 \mathrm{ppm})$ and $\mathrm{CDCl}_{3}(\delta=77 \mathrm{ppm})$ as internal standards, respectively. Also DEPT, gDQ-COSY, $\mathrm{gHSQC}$, and $\mathrm{gHMBC}$ experiments were performed in $\mathrm{CDCl} 3$.

\section{FTIR}

The FTIR spectrum of ambroxol's unknown impurity was recorded on the Perkin Elmer model spectrum series FTIR as KBR pellets. 


\section{Mass Spectrometer}

The ESI mass spectrum of ambroxol's unknown impurity was recorded on the 4000-QTrap LC-MS/MS system. The sample was introduced into the system through HPLC by bypassing the column.

\section{Results and Discussion}

The purpose of this work was to study the stability of ambroxol syrup under stressed conditions. A small quantity of syrup was kept at $40^{\circ} \mathrm{C} / 75 \% \mathrm{RH}$ in stability chambers for about 6 months.

The initial purity and that after the stressed conditions were studied by HPLC. The chromatogram revealed one unknown impurity formed during the accelerated stress conditions. The unknown impurity was eluted at the relative retention time (RRT) 0.68 which was referred to as Impurity I. Impurity I was isolated by preparative HPLC and the structure was identified by spectroscopic techniques (IR, NMR, and LC-MS/MS).

\section{FTIR}

The FTIR spectrum of the ambroxol impurity is shown in Fig. 3. The assignments are mentioned in Table 1.

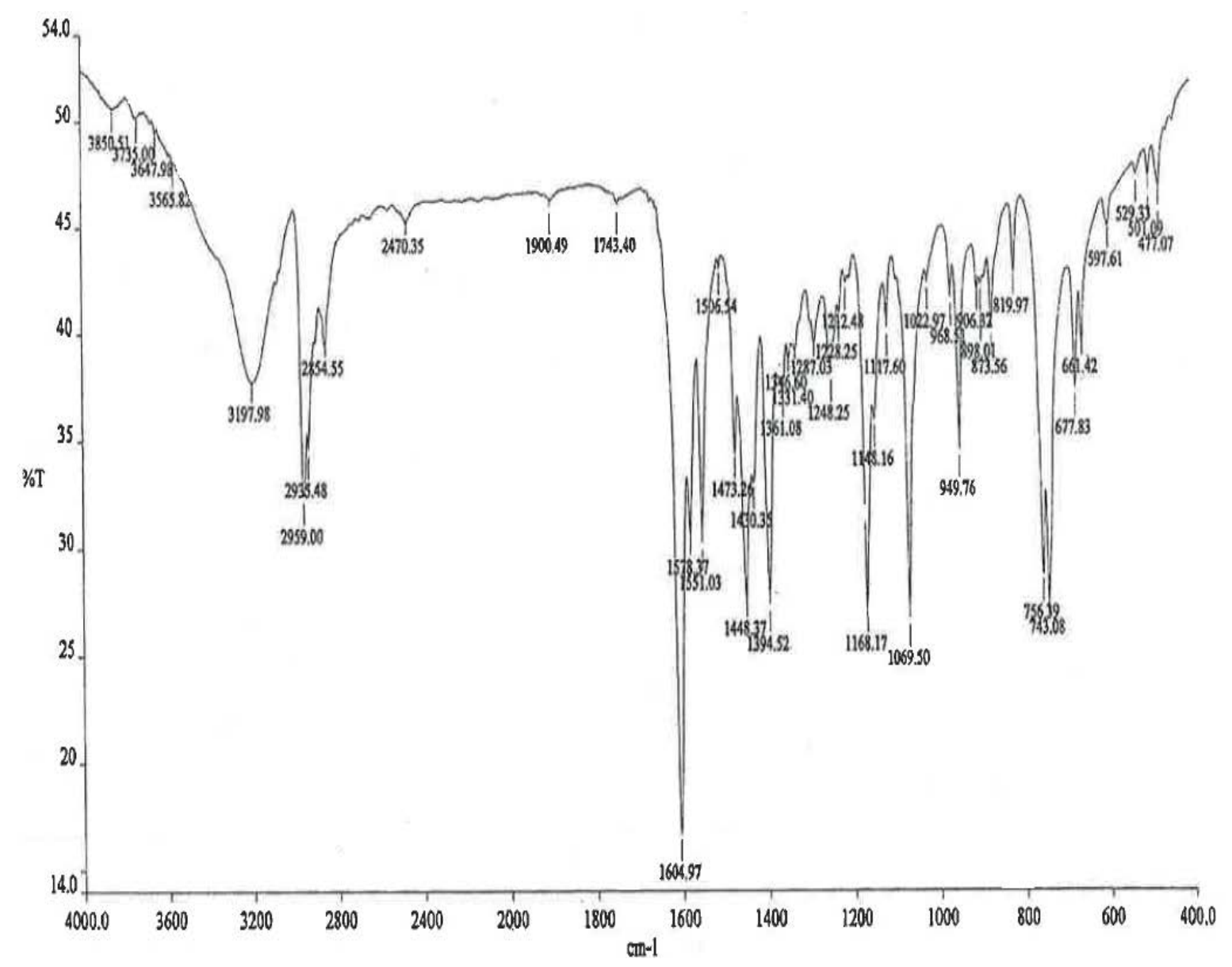

Fig. 3. FTIR spectrum of ambroxol's unknown impurity 
Tab. 1. IR assignments of ambroxol's unknown impurity

\begin{tabular}{lcc}
\hline Wave Number $\left(\mathbf{c m}^{-1}\right)$ & Assignment & Mode of vibration \\
\hline 3198 & $-\mathbf{O}-\mathbf{H}$ & Stretching \\
$2959,2935,2854$ & Aliphatic -C-H & Stretching \\
1605,1551 & Aromatic $-\mathbf{C}=\mathbf{C}$ & Stretching \\
1448,1394 & Aliphatic $-\mathbf{C}-\mathbf{H}$ & Bending \\
1168 & $-\mathbf{C}-\mathbf{O}$ & Stretching \\
1069 & $-\mathbf{C}-\mathbf{N}$ & Stretching \\
756,743 & Aromatic $-\mathbf{C}-\mathbf{H}$ & Bending \\
\hline
\end{tabular}

Tab. 2. NMR assignments of ambroxol's unknown impurity

\begin{tabular}{|c|c|c|c|c|c|c|c|}
\hline Atom $^{1}$ & ${ }^{1} \mathrm{H}$ & $\delta$ (ppm) & $\mathrm{J}(\mathrm{Hz})^{2}$ & ${ }^{13} \mathrm{C}$ & COSY & HSQC & DEPT \\
\hline 2 & $1 \mathrm{H}$ & 7.19 & $\mathrm{~s}$ & 150.3 & - & $(2 \mathrm{H}, 7.19)$ & $\mathrm{CH}$ \\
\hline 4 & - & - & - & 120.1 & - & - & - \\
\hline 5 & $1 \mathrm{H}$ & 7.55 & $\mathrm{~d}, 2.5$ & 134.5 & - & $(5 \mathrm{H}, 7.55)$ & $\mathrm{CH}$ \\
\hline 6 & - & - & - & 116.5 & - & - & - \\
\hline 7 & $1 \mathrm{H}$ & 6.92 & $\mathrm{~d}, 2.5$ & 127.7 & - & $(7 \mathrm{H}, 6.92)$ & $\mathrm{CH}$ \\
\hline 8 & - & - & - & 123.2 & - & - & - \\
\hline 9 & - & - & - & 139.8 & - & - & - \\
\hline 10 & $2 \mathrm{H}$ & 4.48 & $s$ & 43.6 & - & $(10 \mathrm{H}, 4.48)$ & $\mathrm{CH}_{2}$ \\
\hline 11 & $1 \mathrm{H}$ & 3.12 & $\mathrm{~m}$ & 60.7 & $\begin{array}{l}(12,16 \mathrm{Ha}, 1.64) \\
(12,16 \mathrm{He}, 1.88)\end{array}$ & $(11 \mathrm{H}, 3.12)$ & $\mathrm{CH}$ \\
\hline 12,16 & $2 \mathrm{Ha}$ & 1.64 & $\mathrm{dq}$ & 28.0 & $\begin{array}{c}(12,16 \mathrm{He}, 1.88) \\
(13,15 \mathrm{Ha}, 1.42) \\
(11 \mathrm{H}, 3.12)\end{array}$ & $(12,16 \mathrm{Ha}, 1.64)$ & $\mathrm{CH}_{2}$ \\
\hline & $2 \mathrm{He}$ & 1.88 & $\mathrm{~m}$ & - & $\begin{array}{c}(12,16 \mathrm{Ha}, 1.64) \\
(11 \mathrm{H}, 3.12)\end{array}$ & $(12,16 \mathrm{He}, 1.88)$ & - \\
\hline \multirow[t]{2}{*}{13,15} & $2 \mathrm{Ha}$ & 1.42 & $\mathrm{dq}, 12.5$ & 34.1 & $\begin{array}{c}(13,15 \mathrm{He}, 2.12) \\
(12,16 \mathrm{Ha}, 1.64) \\
(14 \mathrm{H}, 3.64)\end{array}$ & $(13,15 \mathrm{Ha}, 1.42)$ & $\mathrm{CH}_{2}$ \\
\hline & $2 \mathrm{He}$ & 2.12 & $d, 12.5$ & - & $\begin{array}{c}(13,15 \mathrm{Ha}, 1.42) \\
(14 \mathrm{H}, 3.64)\end{array}$ & $(13,15 \mathrm{He}, 2.12)$ & - \\
\hline 14 & $1 \mathrm{H}$ & 3.64 & $\mathrm{~m}$ & 69.3 & $\begin{array}{l}(13,15 \mathrm{Ha}, 1.42) \\
(13,15 \mathrm{He}, 2.12)\end{array}$ & $(14 \mathrm{H}, 3.64)$ & $\mathrm{CH}$ \\
\hline
\end{tabular}

\section{NMR Study}

The ${ }^{1} \mathrm{H}$ and ${ }^{13} \mathrm{C}$ NMR spectrum of ambroxol's unknown impurity are shown in Fig. 4 \& 5 . The DEPT experiment revealed the presence of methine groups as positive peaks, while methylene showed as negative peaks which is displayed in Fig. 6. The GDQ-COSY and gHSQC spectra (Fig. $7 \& 8$ ) helped to identify the $1 \mathrm{H}-1 \mathrm{H}$ and $1 \mathrm{H}-13 \mathrm{C}$ correlations. The gHMBC spectrum helped in assigning the quaternary carbons (Fig. 9). In the ID nOe 
experiment (Fig. 10), irradiated methylene protons at $4.48 \mathrm{ppm}$ (position 10) showed the connectivity through space with the protons at 6.92 and $3.12 \mathrm{ppm}$ (Position 7 and 11, respectively). This confirmed the double bond formation at position 2 . The NMR assignments are given in Table 2.

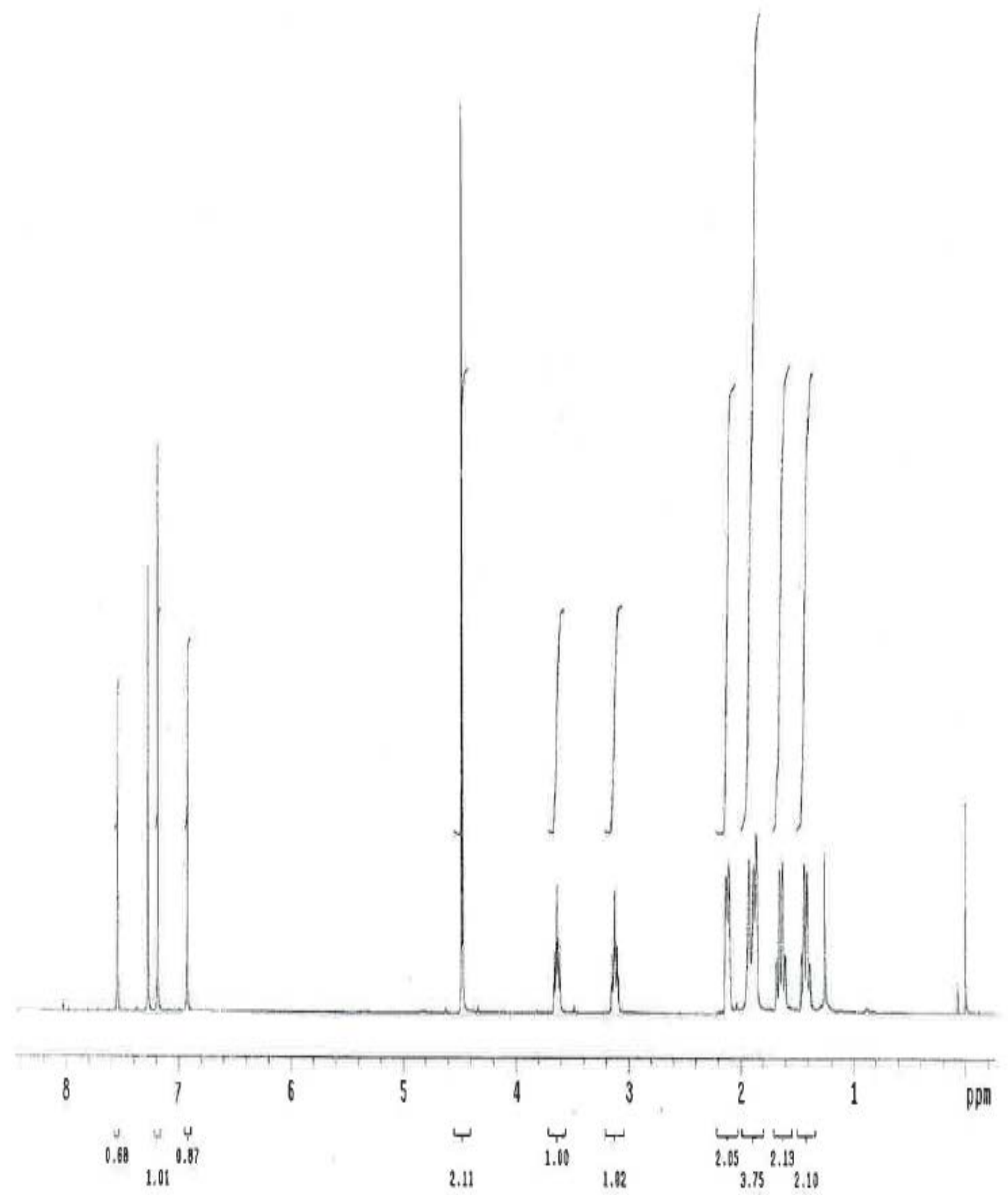

Fig. 4. ${ }^{1} \mathrm{H}$ NMR spectrum of ambroxol's unknown impurity in $\mathrm{CDCl}_{3}$ 
Iafr: 500ketz

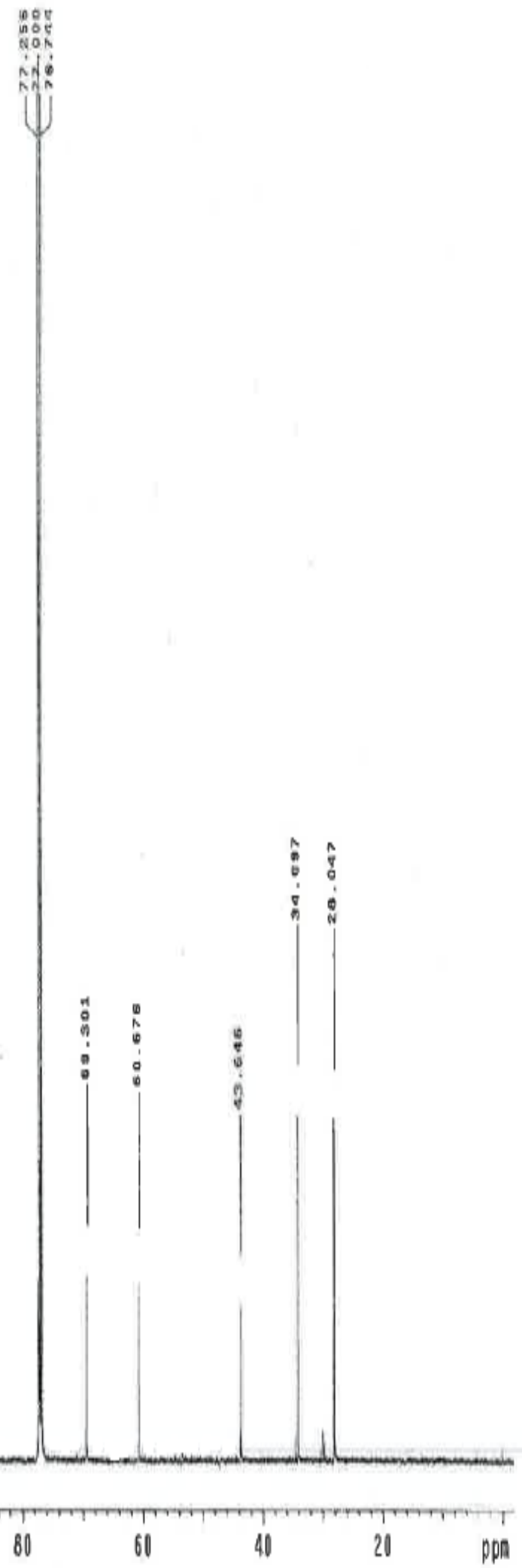

Fig. 5. $\quad{ }^{13} \mathrm{C}$ NMR spectrum of ambroxol's unknown impurity in $\mathrm{CDCl}_{3}$ 

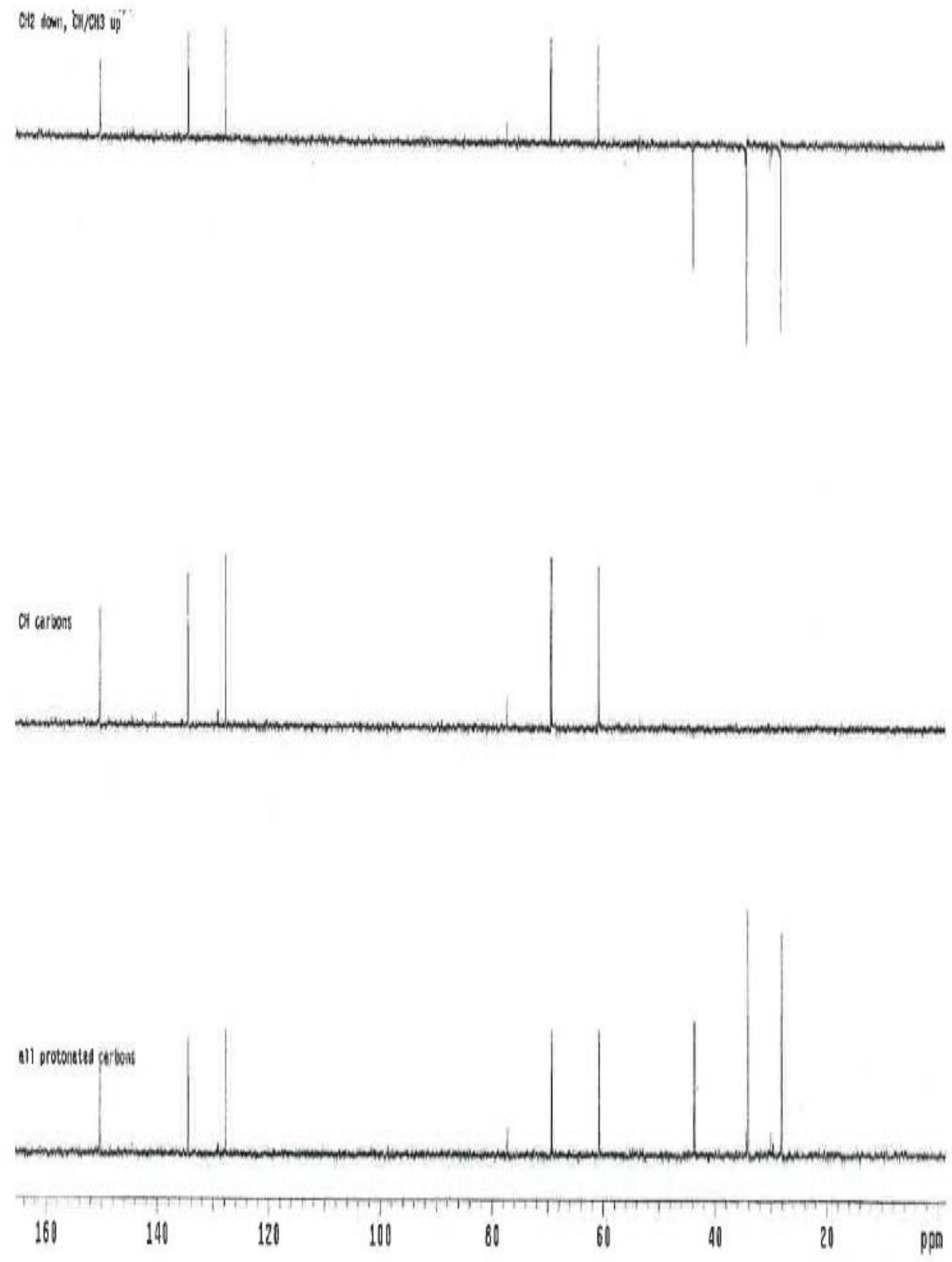

Fig. 6. DEPT spectrum of ambroxol's unknown impurity in $\mathrm{CDCl}_{3}$ 


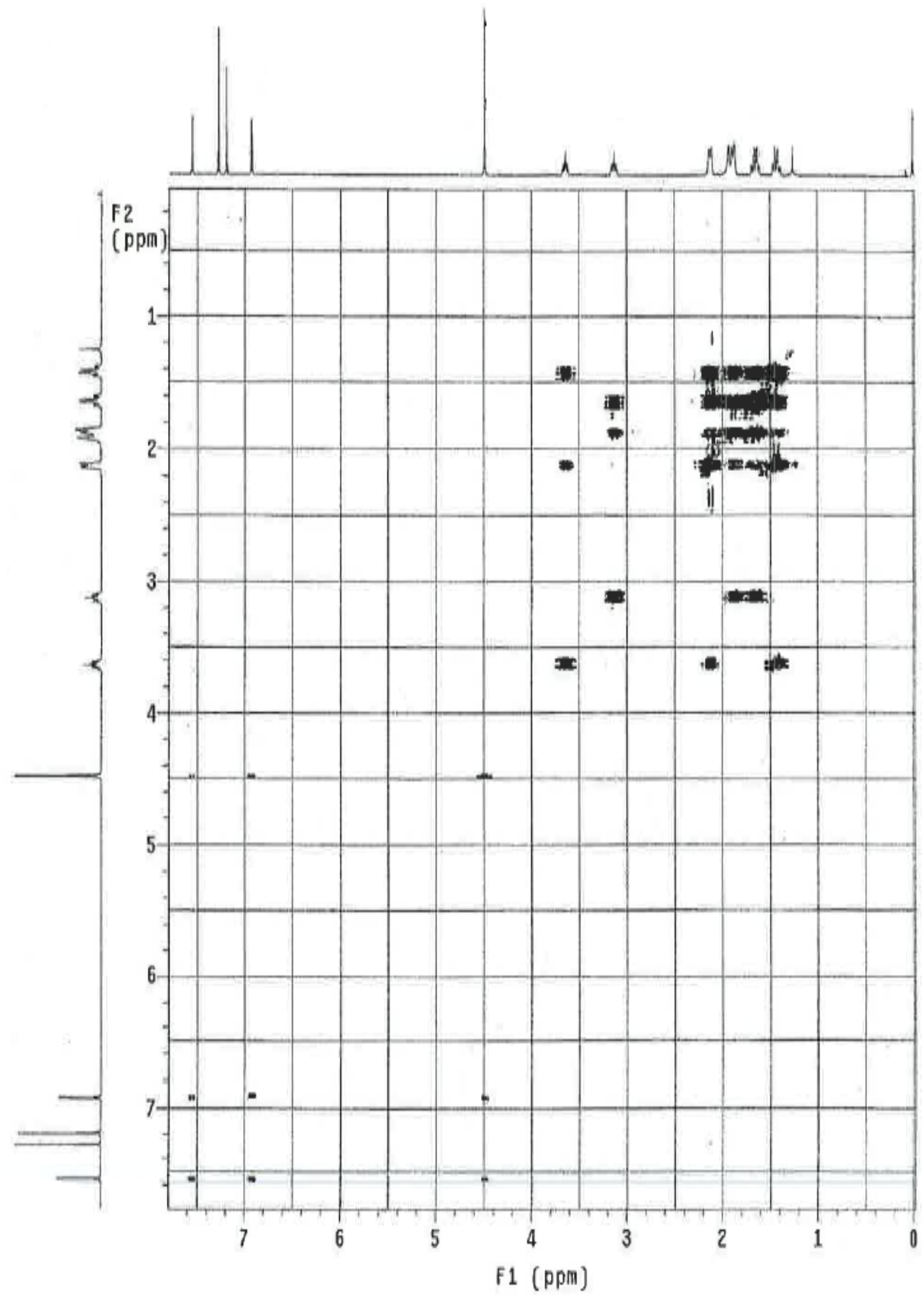

Fig. 7. gDQ-COSY spectrum of ambroxol's unknown impurity in $\mathrm{CDCl}_{3}$ 


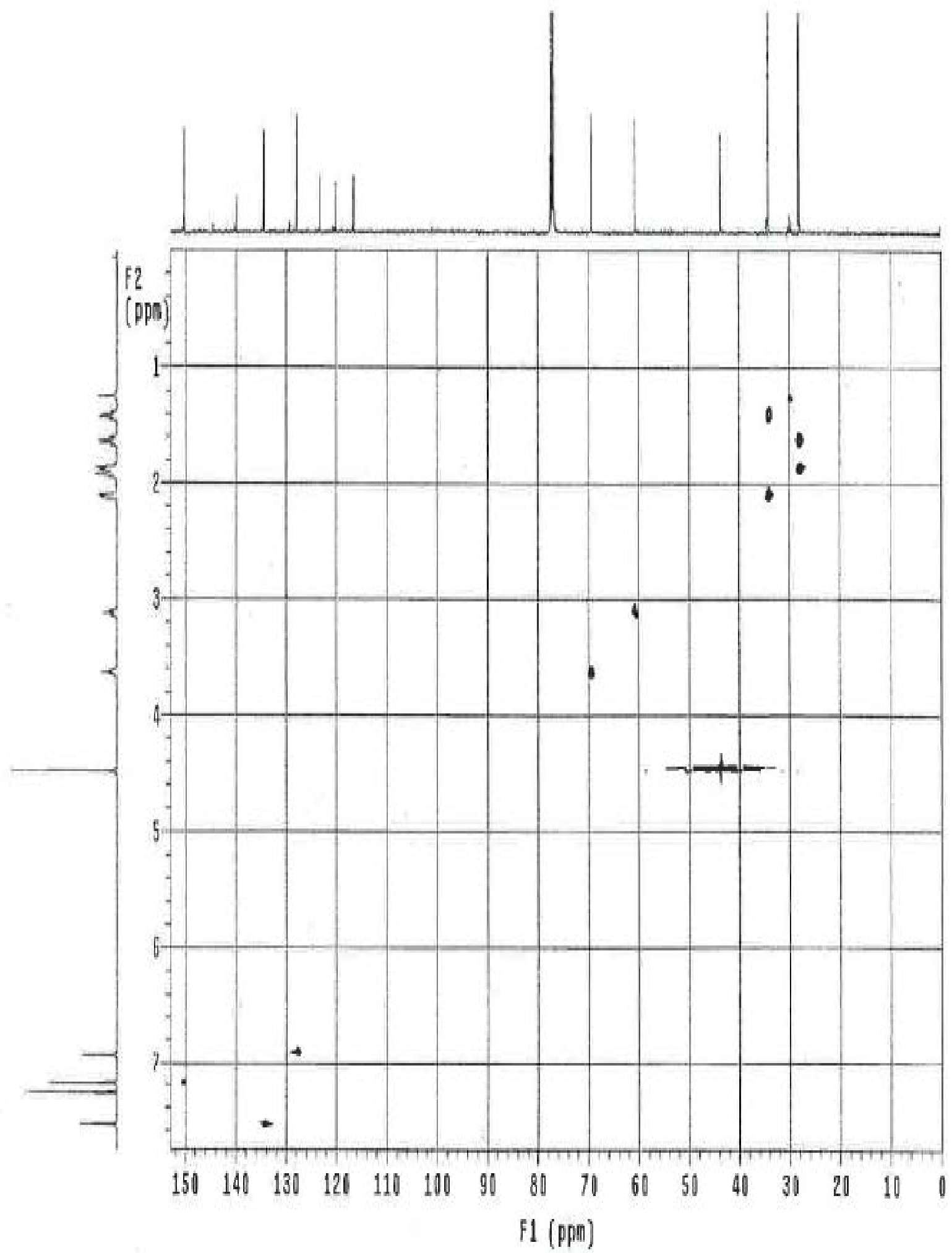

Fig. 8. gHSQC spectrum of ambroxol's unknown impurity in $\mathrm{CDCl}_{3}$ 


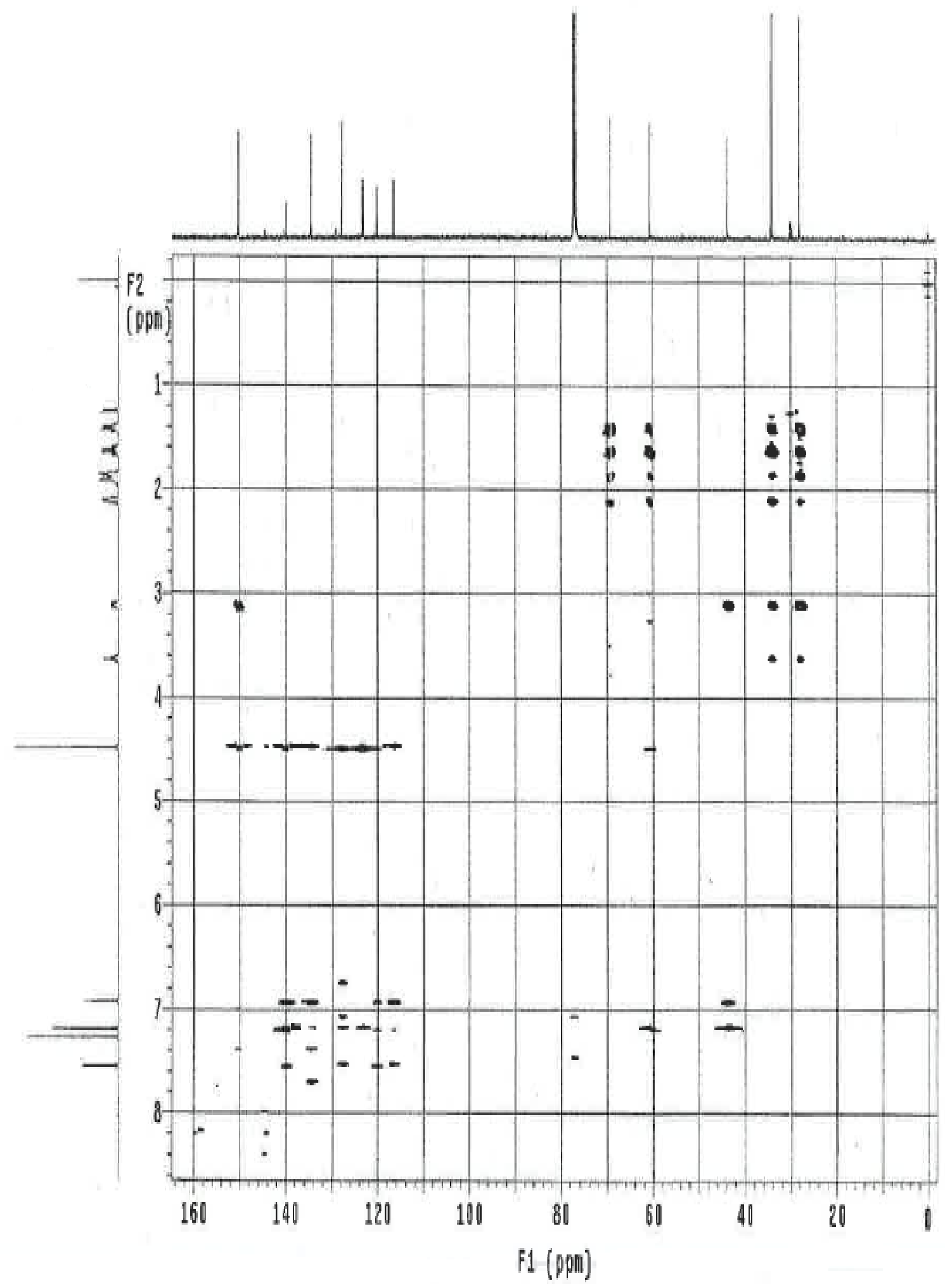

Fig. 9. gHMBC spectrum of ambroxol's unknown impurity in $\mathrm{CDCl}_{3}$ 


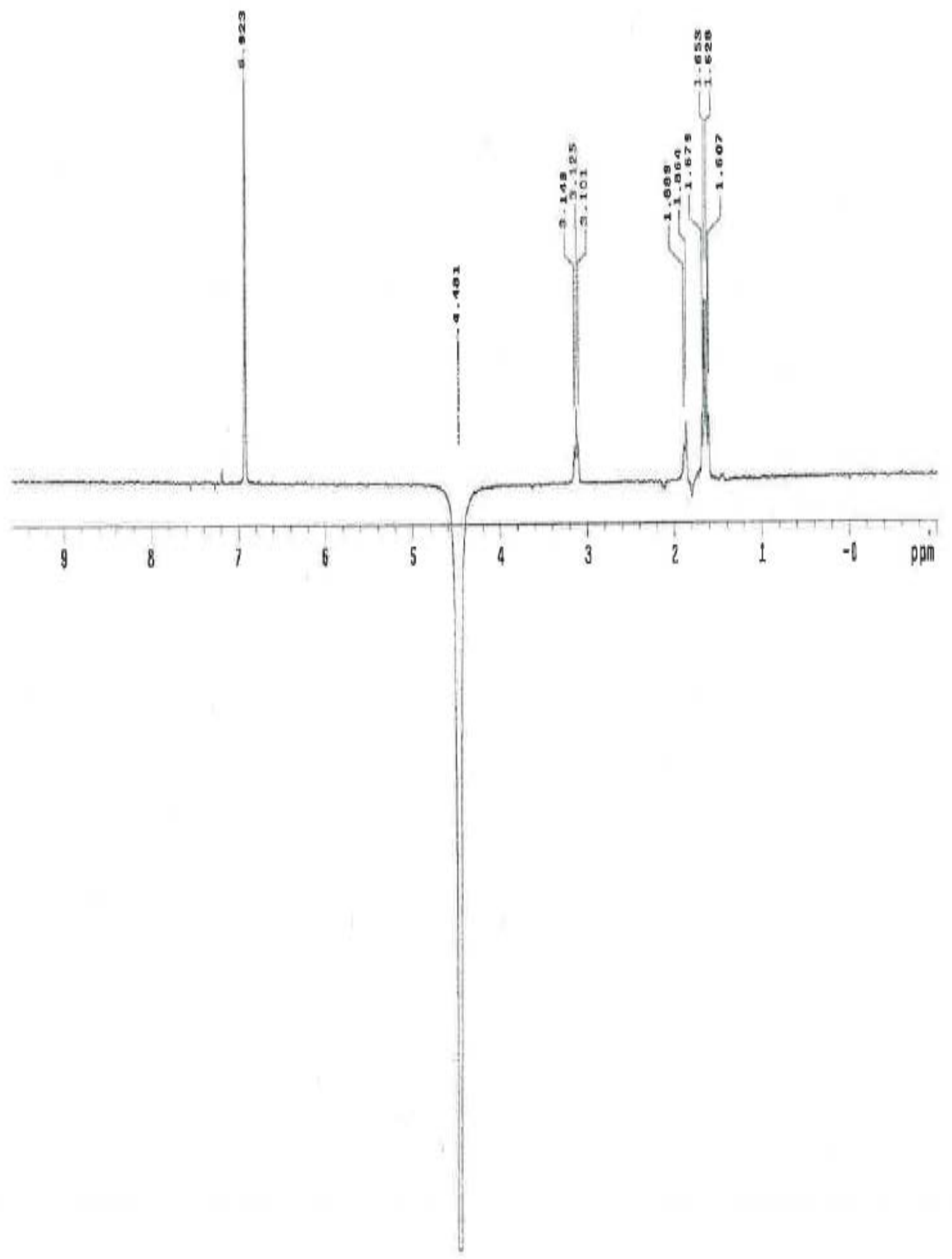

Fig. 10. ID nOe spectrum of ambroxol's unknown impurity in $\mathrm{CDCl}_{3}$ 


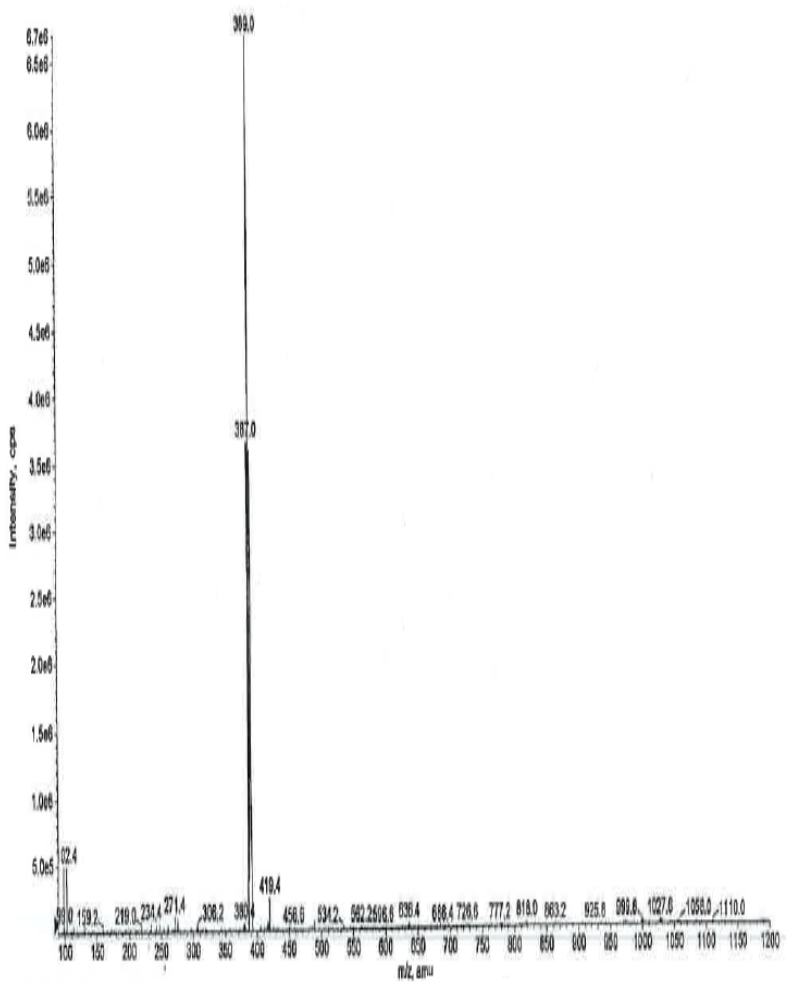

Fig. 11. The ESI +ve mass spectrum of ambroxol's unknown impurity

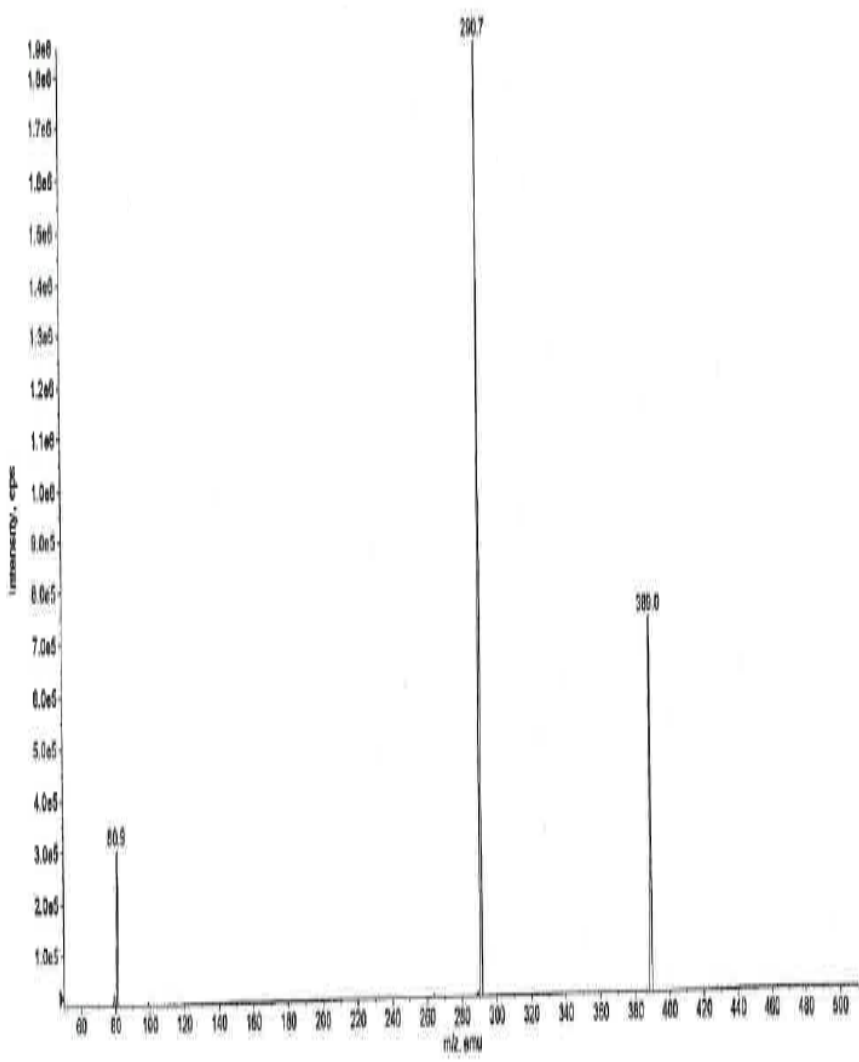

Fig. 12. The LC/MS/MS mass spectrum of ambroxol's unknown impurity 


\section{Mass Spectral Data}
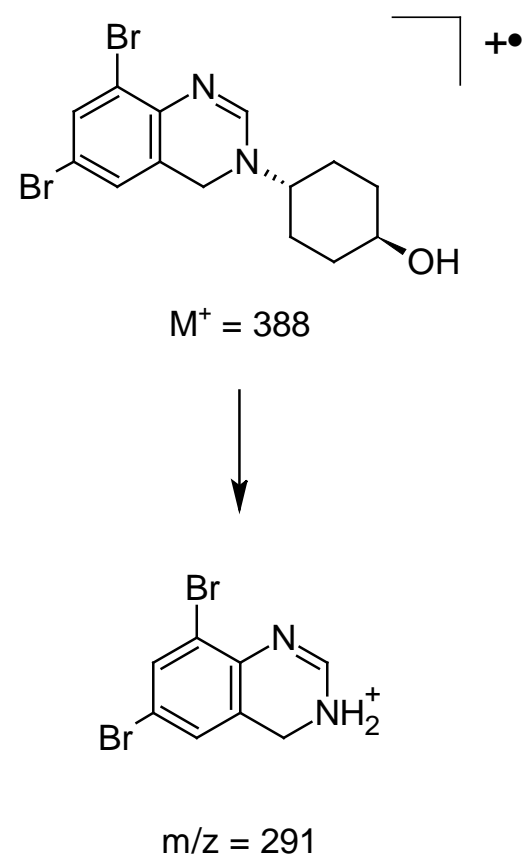

Fig. 13. Plausible fragmentation pattern for the unknown impurity from the LC-MS/MS spectrum

The ESI +ve ionization spectrum (Fig. 11) data of ambroxol's unknown impurity displayed the protonated molecular ion $[\mathrm{M}+\mathrm{H}]+$ at $\mathrm{m} / \mathrm{z} 389$ corresponding to the molecular formula $\mathrm{C}_{14} \mathrm{H}_{16} \mathrm{Br}_{2} \mathrm{~N}_{2} \mathrm{O}$. The LC-MS/MS scan (Fig. 12) confirmed the molecular formula. The plausible fragmentation pattern for the unknown impurity based on the LC-MS/MS scan is shown in Fig. 13.

From the IR, NMR, and mass spectral data, the structure of ambroxol's unknown impurity was confirmed as trans-4-(6,8-dibromoquinazolin-3(4H)-yl)cyclohexanol. The elucidated structure is shown in Fig. 14.<smiles>OC1CCC(N2C=Nc3c(Br)cc(Br)cc3C2)CC1</smiles>

Fig. 14. Structure of ambroxol's unknown impurity

\section{Conclusion}

One unknown impurity in ambroxol syrup was generated during the accelerated stressed conditions. This impurity was isolated by preparative HPLC and characterized as trans-4(6,8-dibromoquinazolin-3(4H)-yl)cyclohexanol by IR, NMR, and LC-MS/MS. Such ad- 
vanced methods will be utilized for structure elucidation of impurities of other active ingredients.

\section{Acknowledgement}

The authors wish to thank the management of Dr. Reddy's Laboratories for permitting this work to be published. Cooperation of all colleagues of the Analytical Research division is gratefully acknowledged.

Dr. Reddy's internal publication number for this manuscript is PUB-00281-13.

\section{Authors' Statement}

Competing Interests

The authors declare no conflict of interest.

\section{References}

[1] Budavari S.

The Merck Index: An Encyclopedia of Chemicals, Drugs and Biologicals.

Merck Research Laboratories Division of Merck and Co., Inc. Whitehouse Station.

Merck Index: 13th ed., 2001: 67-68.

[2] Nudelman NS.

Estabilidad de Medicamentos.

El Ateneo: Buenos Aires, 1975.

[3] Kommanaboyina B, Rhodes CT.

Trends in stability testing, with emphasis on stability during distribution and storage.

Drug Dev Ind Pharm. 1999; 25: 857-868

http://dx.doi.org/10.1081/DDC-100102246

[4] $\quad \mathrm{ICH}-\mathrm{Q} 3 \mathrm{~B}(\mathrm{R} 2)(2006)$.

Impurities in New Drug Products

[5] Ambroxol Hydrochloride.

(Ph Eur monograph 1489). British Pharmacopeia; 2010: 118-119.

[6] Kuchekar BS, Shinde GS, Naikwadi IT, Todkar KJ, Kharade SV.

Specrtophotometric estimation of ambroxol hydrochloride in tablets.

Indian J Pharm Sci. 2003; 65: 193-195.

[7] Reddy MN, Rao KV, Swapna M, Sankar DG.

Spectrophotometric determination of ambroxol.

East Pharmacist. 1998; 125-126.

[8] Zafer D, Hasan B, Nilgun GG.

Quantitative determination of ambroxol in tablets by derivative UV spectrophotometric method and HPLC.

J Pharm Biomed Anal. 2003; 31: 867-872.

http://dx.doi.org/10.1016/S0731-7085(02)00664-7

[9] Gunawan I, Ratna H.

Quantitative determination of ambroxol hydrochloride in tablets.

J Pharm Biomed Anal. 1993; 11: 781-784.

http://dx.doi.org/10.1016/0731-7085(93)80189-8 
[10] Maarit $\mathrm{H}$, Coral B.

Validation of an HPLC method for the quantification of ambroxol hydrochloride and benzoic acid in a syrup as pharmaceutical form stress test for stability evaluation.

J Pharm Biomed Anal. 2001; 24: 1005-1010.

http://dx.doi.org/10.1016/S0731-7085(00)00533-1

[11] Botterblom MHA, Janssen TJ, Guelen PJM, Vree TB.

Rapid and sensitive determination of ambroxol in human plasms and urine by high-performance liquid chromatography.

J Chromatogr. 1987; 421: 211-215.

http://dx.doi.org/10.1016/0378-4347(87)80400-0

[12] Flores-Murrieta FJ, Hoyo-Vadillo C, Hong E, Castaneda-Hernandez G.

Assay of ambroxol in human plasma by high-performance liquid chromatography with amperometric detection.

J Chromatogr B. 1989; 490: 464-469.

http://dx.doi.org/10.1016/S0378-4347(00)82807-8

[13] John EK, Eleftheria TM, Theodora AB.

High performance liquid chromatographic determination of ambroxol in the presence of different preservatives in pharmaceutical formulations.

J Pharm Biomed Anal. 2000; 23: 469-475.

http://dx.doi.org/10.1016/S0731-7085(00)00318-6

[14] Colombo L, Marcucci F, Marini MG, Pierfederici P, Mussini E.

Determination of ambroxol in biological material by gas chromatography with electron-capture detection.

J Chromatogr B. 1990; 530: 141-147.

http://dx.doi.org/10.1016/S0378-4347(00)82313-0

[15] Schmid J.

Assay of ambroxol in biological fluids by capillary gas-liquid chromatography.

J Chromatogr B. 1987; 414: 65-75.

http://dx.doi.org/10.1016/0378-4347(87)80025-7

[16] Dalibor S, Jitka H, Raquel LCF, Maria C BSM, Montenegro, Petr S.

Determination of ambroxol hydrochloride, methylparaben and benzoic acid in pharmaceutical

preparations based on sequential injection technique coupled with monolithic column.

J Pharm Biomed Anal. 2006; 40: 287-293.

http://dx.doi.org/10.1016/j.jpba.2005.07.032

[17] Hohyun K, Jeong-Yeon Y, Sang BH, Hee JL, Kyung RL.

Determination of ambroxol in human plasma using LC-MS/MS.

J Pharm Biomed Anal. 2003; 32: 209-216.

http://dx.doi.org/10.1016/S0731-7085(03)00059-1

[18] Pospisilova M, Polasek M, Jokl V.

Determination of ambroxol or bromhexine in pharmaceuticals by capillary isotachophoresis.

J Pharm Biomed Anal. 2001; 24: 421-428.

http://dx.doi.org/10.1016/S0731-7085(00)00448-9

[19] Tomas PR, Carmen ML, Antonio S, Eva B.

Sensitive method for the determination of ambroxol in body fluids by capillary electrophoresis and fluorescence detection.

J Chromatogr B. 2000; 742: 205-210.

http://dx.doi.org/10.1016/S0378-4347(00)00150-X

[20] Tollsten L.

In: Identification and Determination of Impurities in Drugs.

Grog S, ed.

Elsevier: Amsterdam, 2000, pp 266. 